\title{
Continuous or intermittent walking, the effect on glycated hemoglobin in sedentary employees during 10 -week intervention
}

\author{
Mynor Rodriguez-Hernandez ${ }^{\mathrm{a}, \mathrm{b}^{*}}$ (D) \& James R. McDonald ${ }^{\mathrm{b}}$, Danielle W. Wadsworth ${ }^{\mathrm{b}}$ \\ a Department of Education Sciences, University of Costa Rica, San Ramon, Alajuela, Costa Rica, 20201 \\ b School of Kinesiology, Auburn University, Auburn, AL USA 36849 \\ *Corresponding author Email: mynor.rodriguez@ucr.ac.cr \\ DOI: https://doi.org/10.34256/ijpefs2114
}

Received: 17-02-2021, Revised: 22-03-2021; Accepted: 24-03-2021; Published: 26-03-2021

\begin{abstract}
To examine long term changes on glycated hemoglobin in sedentary employees exposed to two different walking programs during a 10-week intervention. A total of 68 sedentary employees participated in a 10week walking intervention and were randomly assigned to one of three groups: intermittent walking, continuous walking or control group. Hemoglobin A1cNOW+ device tested glycated hemoglobin and accelerometry assessed physical activity. Results showed glycated hemoglobin significantly decreased over the ten weeks (5.82 \pm 0.49 , $5.66 \pm 0.44) F(1,64)=4.229, p=.044)$ in the continuous walking group. Post-Hoc test showed the continuous walking group was significantly affected, $\mathrm{F}=8.463, \mathrm{p}=.009$, with a large size effect $\mathrm{n} 2=.297$. There were no changes within the intermittent group $(5.69 \pm 0.63,5.63 \pm 0.6)$ or control group $(5.59 \pm 0.6,5.6 \pm 0.54)(p>0.05)$. Accelerometry showed a main effect of time by group interaction $F(4,124)=4.688, p=0.001)$. Post-Hoc indicated that the continuous walking group took significantly longer bouts of moderate to vigorous intensity walking at week- 6 compared to pre-test $(p=0.006)$ at this could have influenced the results, there were no changes in the length of bouts in the intermittent or control groups $(p>0.05)$. Sedentary employees who perform a moderate intensity continuous walking program show benefits in controlling blood glucose, thereby, reducing the risk of developing type 2 diabetes.
\end{abstract}

Keywords: Physical activity, Sedentary behavior, Blood glucose, Glycated hemoglobin

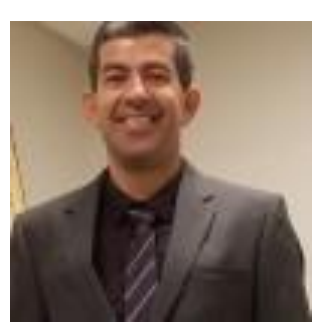

Dr. Mynor RodriguezHernandez lives in San Ramon Costa Rica, He is a full Professor at the University of Costa Rica, Western Campus. His research focuses on projects that would impact community needs in terms of physical activity, health, and quality of life. All contributions of physical activity behavior, sedentary behavior, sitting time, breaking sedentary time to health and quality of life. As well as possible ways to increase exercise adherence in adult populations. He is member of the American College of Sports Medicine, the International Society for Physical Activity and Health and of the American Network for Research in Human Movement Sciences. He has participated as a presenter in international conferences. He also collaborates as reviewer of important journals related to the field of human movement sciences.

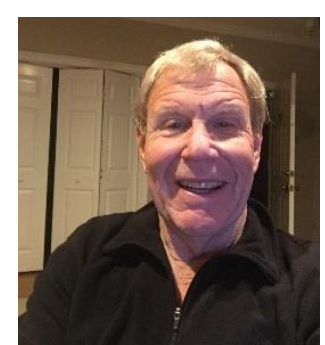

Dr. McDonald has been a clinical professor at Auburn University since 2012. His TigerFit laboratory conducts health and fitness testing for the Auburn community. The program allows students to get "hands-on" experience in all aspect of health and fitness testing and prescription working with a cross section of the local community. Dr. McDonald came to academia later in life following a 30 -year career in the U.S. Air Force where he served as a fighter pilot and military diplomat, retiring at the rank of Colonel. After a few years working in industry, he came to Auburn in pursuit of a PhD in exercise physiology and after completing the degree, he was hired as clinical faculty. He has done research in basic muscle oxygen on-kinetics, lactate metabolism, and role of exercise in weight loss and health across various human populations. 


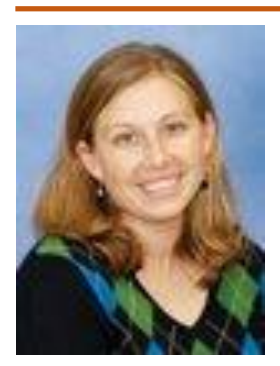

Dr. Danielle D. Wadsworth is an associate professor at Auburn University in the School of Kinesiology and Director of the Exercise Adherence and Obesity prevention laboratory. Her research focuses on identifying environmental, psychological and social underpinnings of exercise adherence and translating these findings to effective evidence-based interventions, primarily for women and children. Dr. Wadsworth has served as a coinvestigator on National Institutes of Health and Robert Wood Johnson Foundation grants aimed at examining the impact of physical activity policies on children's physical activity levels at school and during physical education. Over the past year, she has concentrated her efforts on identifying factors to long-term exercise adherence in young children. Dr. Wadsworth lives with her husband and three children in Auburn, Alabama.

\section{Introduction}

Sedentary behavior and physical activity are two inversely related behavioral scenarios that have significant effects on health outcomes. While physical activity produces positive effects on overall health [1] chronic sedentary behavior is linked to health impairments such as increased obesity, diabetes, cardiovascular disease, cancer, and early mortality [24]. With sedentary behavior leading to the development of several health complications, it is important to consider the positive effect that small amounts of exercise may produce on overall well-being [1]. Walking behavior is linked to reductions in type 2 diabetes (T2D) risk. A previous review that included 300,000 participants, showed that T2D was 0.69 (95\% CI $0.58-0.83$ ) for regular participation in physical activity of moderate intensity as compared with being sedentary. Also, the relative risk was $0.70(0.58-0.84)$ for moderate walking approximately 2.5 hours/week the risk was 0.69 (95\% CI $0.58-0.83$ ) compared to inactive [5]. An additional prospective study that examined approximately 70,000 healthy female nurses over 8 years, determined that a higher walking activity level was associated with significant reductions in T2D risk [6].

High levels of blood glucose are related to risk of developing cardiovascular disease (CVD) and increase the risk of all-cause mortality. To control glycemic levels in long term, patients with T2D should stablish the goal of keeping glycated hemoglobin (HbA1c) below 7\% [7-10], which can reduce the long term complications in about 76\% [11]. According to the experts, HbA1c indicates the average blood glucose levels over several months and it is not a measure that changes over the course of one day when the blood glucose can variate depending on the content and frequency of the meals and physical activity achieved [12-14].

Previous epidemiological studies have shown that small reductions (1\%) on $\mathrm{HbA1c}$, is associated with $14 \%$ to $21 \%$ of reduction on cardiovascular and diabetes complications and $37 \%$ microvascular detriments [15]. Some studies indicate that the intensity level of the exercise is related to improvements of blood glucose control as reflected in reductions in $\mathrm{HbA1c}$ [16].

Looking at studies that targeted participants with T2D with twelve or more weeks interventions, and focused on different models of exercise training, some have found significant differences post intervention in favor of reductions of $\mathrm{HbA1C}[8,17,18]$. Meanwhile, results obtained from a meta-analysis that included exercise interventions with $\geq 8$ weeks [19], show that when exercise groups were compared to control groups, the weighted mean difference (WMD) HbA1c was significantly lower in the exercise groups, pooling the post-intervention results, the exercise groups had a lower HbA1c compared with the control groups (7.65\% vs $8.31 \%$; WMD, $-0.66 \% ; P<.001)$. However, others have not found significant changes. For example, in a 16 week aerobic training conducted by Tessier and colleagues, no significant changes regarding $\mathrm{HbA1C}$ were found [20]. Although physical activity has constantly been linked to reductions in T2D and results seem promising $[21,22]$, the effect of walking on $\mathrm{HbA1C}$ needs to be further clarified [23], particularly in terms of which type of walking activity has the greatest effective on HbA1c and also, it is important to clarify the timeline to see positive changes on this variable. Furthermore, most of the interventions have included participants with type 2 diabetes, focusing on physical activity and its effect on T2D versus a prevention model.

Intermittent walking activity to disrupt sedentary behavior may be a modality of exercise to reduce the risk of developing T2D [24]. In acute interventions, some studies have compared intermittent physical activity versus continuous physical activity. In the short term, intermittent physical activity appears to attenuate, to a larger extent, glucose excursions compared to 1 -h morning exercise time and intensity matched [25]. In T2D patients and in a counterbalanced acute intervention, intermittent 
walking improved glycemic control compared to a time duration-matched continuous walking activity [26]. Both models, independently of continuous or intermittent physical activity, have been determined to provide similar glucose outcomes when time and intensity are matched, meaning that physical activity is beneficial to improve blood glucose levels [27].

However, to our knowledge, most interventions have focused on acute effects of physical activity on blood glucose levels when comparing intermittent versus continuous physical activity. Thus, our experimental study investigated the long-term effect of two different walking activity protocols in free-living conditions on HbA1c in sedentary office workers.

\section{Materials and Methods}

The methodology for this study has been published before $[28,29]$. For instance, this section of the study adds the particular effect of walking activity on HbA1c. A brief procedure is defined below.

\subsection{Participants and study protocol}

This study involved initially 84 sedentary office employees, males and females who participated in a 10 -week walking- free living conditions- intervention.
The sample size was determined following Cohen's recommendations [30]. Then, for a conservative calculation $\mathrm{a}_{1}=.05, \mathrm{r}=.30$, and power $=.80$ the desire sample size was 68 . Certainly, a total of 68 subjects completed the trial as explained before [28].

The walking intervention included a 10-week program consisting of two walking protocols; multiple micro-bout and continuous walking. For both experimental groups, time and intensity were matched, and with intensity and duration increasing incrementally over the 10- week program (Figure 1).

All procedures described herein were approved by the Auburn University Institutional Review Board and conformed to the standards set by the latest revision of the Declaration of Helsinki. Prior to participation, all subjects were asked to sign an informed consent and complete the Physical Activity Readiness Questionnaire (PAR-Q) followed by baseline assessments for height, weight, $\mathrm{HbA1C}$ and physical activity. Height, weight and HbA1c measures were taken again at week 11 . Physical activity was measured with an ActiGraph GT3X (ActiGraph Corp., Pensacola, $\mathrm{FL})$, accelerometer worn on the waist at baseline, week 6 and week 11.

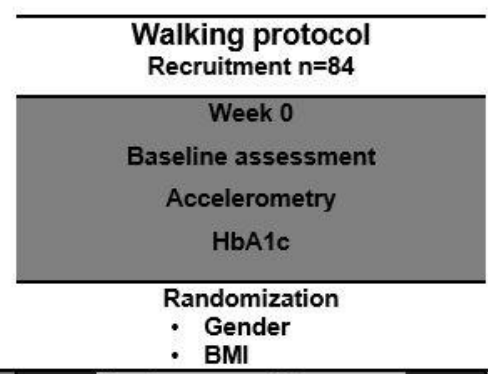

\begin{tabular}{|c|c|c|}
\hline $\begin{array}{l}\text { Intermittent walking group } \\
\qquad n=28\end{array}$ & $\begin{array}{c}\text { Continuous walking group } \\
\qquad \mathrm{n}=28\end{array}$ & $\begin{array}{c}\text { Control group } \\
n=28\end{array}$ \\
\hline $\begin{array}{ll}\text { - } & \text { Multiple bouts/day } \\
\text { - } & \text { Walking program } \\
+ & + \\
\text { - } & \text { Advise } 10,000 \text { steps per day }\end{array}$ & $\begin{array}{l}\text { - } 1 \text { single bout /day } \\
\text { - Walking program } \\
+ \\
\text { - Advise } 10,000 \text { steps per day }\end{array}$ & 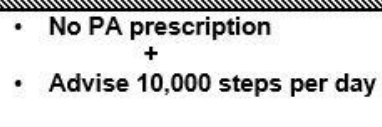 \\
\hline $\begin{array}{l}\text { Week } 1 \\
4 \text { break/5-min/3 day/week 30-60\% HR/3-6 RPE } \\
\text { - Week 2-3 } \\
6 \text { break/5-min/3 day/week 40-60\% HR/4-6 RPE } \\
\text { Week 4-5 } \\
6 \text { break/5-min/4 day/week 40-60\% HR/4-6 RPE }\end{array}$ & $\begin{array}{c}\text { - Week } 1 \\
20 \mathrm{~min} / 3 \text { day/week } 30-60 \% \mathrm{HR} / 3-6 \mathrm{RPE} \\
\text { Week 2-3 } \\
30 \mathrm{~min} / 3 \text { day/week } 40-60 \% \mathrm{HR} / 4-6 \mathrm{RPE} \\
\text { Week } 4-5 \\
30 \mathrm{~min} / 4 \text { day/week } 40-60 \% \mathrm{HR} / 4-6 \mathrm{RPE}\end{array}$ & \\
\hline \multicolumn{3}{|c|}{ Week 6 accelerometry assessment } \\
\hline $\begin{array}{l}\text { Week 6-7 } \\
6 \text { break/5-min/5 day/week 40-60\% HR/4-6 RPE } \\
\text { Week 8-10 } \\
\text { 8 Break/5- min/5 day/week 40-60\% HR/4-6 RPE }\end{array}$ & $\begin{array}{c}\text { - Week 6-7 } \\
30 \mathrm{~min} / 5 \text { day/week } 40-60 \% \mathrm{HR} / 4-6 \mathrm{RPE} \\
\text { Week 8-10 } \\
40 \mathrm{~min} / 5 \text { day/week } 40-60 \% \mathrm{HR} / 4-6 \mathrm{RPE}\end{array}$ & \\
\hline $\begin{array}{l}\text { Post-test week } 11 \\
\quad n=23 \\
\text { Accelerometry }\end{array}$ & $\begin{array}{l}\text { Post-Test week } 11 \\
\quad n=23 \\
\text { Accelerometry }\end{array}$ & $\begin{array}{l}\text { Post-Test week } 11 \\
n=22 \\
\text { Accelerometry }\end{array}$ \\
\hline $\mathrm{HbA1c}$ & $\mathrm{HbA1c}$ & $\mathrm{HbA1c}$ \\
\hline
\end{tabular}

Figure 1 study design in a 10-week intervention. BMI (Body Mass Index), HR (heart rate), RPE (rated perceived exertion). 
At baseline groups were randomized to one of three groups, with equal randomization between males and females and BMI status. The two experimental groups were given walking exercise prescriptions based on group assignments in written and electronic format. A weekly email and three text messages a week were sent to remind and encourage walking participation. The control group was told that " 10,000 steps a day is a minimum for good health". Figure 1 details the intervention design.

\subsection{Measurements}

\subsubsection{Body Mass Index}

Height and weight were assessed using a stadiometer (SECA Model 769, Seca, Hamburg, Germany) and Body Mass Index (BMI) was determined by weight $(\mathrm{kg}) /$ [height $(\mathrm{m})]^{2}$.

\subsubsection{Hemoglobin A1c test}

$\mathrm{AlcNOW}^{+}$system was used to measure hemoglobin HbA1c Polymer Technology Systems, Inc. (Indianapolis, IN). The HbA1c test is a blood test to analyze the average levels of blood glucose over a period of three months to determine diabetes development. Outcomes of the test are interrupted as: normal range below $5.7 \%$, pre-diabetes $5.7-6.4 \%$, and diabetes $6.5 \%$ or above.

When comparing the $\mathrm{AlCNOW}^{+}$system to the National Glycohemoglobin Standardization Program (NGSP) certified method [31], the accuracy of the A1cNOW on average is $99 \%$, meaning that a true 7.0 \%A1c could be approximately $6.9 \% \mathrm{~A} 1 \mathrm{c}$ or $7.1 \% \mathrm{~A} 1 \mathrm{c}$ [32]. A small amount of blood sample (5 microliters $(\mu \mathrm{L}))$ was collected from a finger prick using a 28gauge lancet (Unistick 3 comfort, Owen Mumford, Marietta, GA). The sample was placed in a portable A1CNOW device with a test cartridge and the results were recorded after 5 minutes.

\subsubsection{Physical Activity measures}

To measure Physical Activity behavior an Actigraph accelerometer GT3X (ActiGraph GT3X; ActiGraph Corp., Pensacola, $\mathrm{FL}$ ) was attached on the right hip of each participant for seven days at baseline, week 6 and week 11 . The device is a small trial-axial device weighing $27 \mathrm{~g}$ and measuring $3.8 \mathrm{~cm} \times 3.7 \mathrm{~cm}$. $x$ $1.8 \mathrm{~cm}$. The GT3X records accelerations ranging from 0.05 to $2 \mathrm{~g}$ at a rate of $30 \mathrm{~Hz}$ in three different axes: vertical, antero-posterior, and medio-lateral [33]. Based on previous studies and best practice guidelines $[34,35]$, an epoch length of 1 -minute was chosen as the standard for the current study with a sampling rate of $30 \mathrm{~Hz}$. Additional criteria for analysis include a minimum of 10 hours daily wear time and 3-5 days of monitoring. There is relative consensus of a minimum of 10 hours per day of wear time needed for sampling wake-time behavior with 3-5 days of monitoring required to achieve $80 \%$ reliability for total and moderate-to-vigorous intensity physical activity [3638]. Non-wear time was identified by participants completing a daily log of wearing time and non-wear time was removed from the analysis. Previously validated cut points were used to classify accelerometer data as sedentary $\quad(<100$ counts/minute), moderate ( $<5,999$ counts/minute) and vigorous $(>5,999),[39]$. Light activity was defined as 500-2019 counts per minute [40]. After meeting the above criteria, the data were analyzed to obtain on each assessment a percentage of time per hour spent in sedentary behavior, light, and moderate to vigorous physical activity per group. Also, to clarify the results, a single regular week day of accelerometer data was used to describe participants' physical activity behavior as an example, specifically MVPA.

\subsection{Statistical analysis}

All analyses were performed with SPSS 23.0. To answer the research questions, a mixed design ANOVA approach was performed to examine the main effect over time and the main effect of time and group interaction in HbA1c and physical activity (sedentary behavior, light, and moderate to vigorous physical activity (MVPA). Between factors examined differences between the three groups, whereas, within factors assessed change over time. The Bonferroni Post-Hoc testing was used if a significant interaction occurred.

\section{Results and Analysis}

A total of sixty-eight sedentary office employees completed the intervention. Initial analysis showed that groups did not differ by BMI $p=0.272$. The adherence and attrition rates of the study were $80.95 \%$ and $19.05 \%$ respectively, which is considered positive rates [41, 42].

\subsection{Hemoglobin A1c results}

The analysis show that HbA1c was not significantly different between groups at the onset of the study. The results from the mixed-design ANOVA showed that $\mathrm{HbA1C}$ decreased significantly from pretest to post-test $f(1,64)=5.709, p=.020)$ with a medium size effect of $n^{2}=082$. 


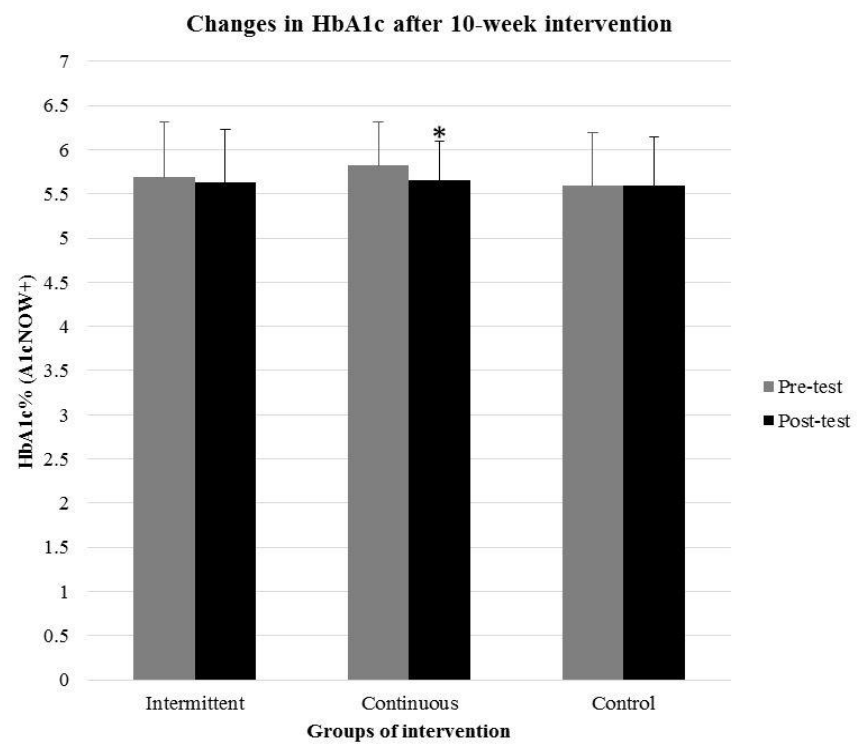

Figure 2 compares the A1cNOW+ results for the three intervention groups at pre-test and post-test.

$*$ significantly different from pre-test $(p<0.05)$
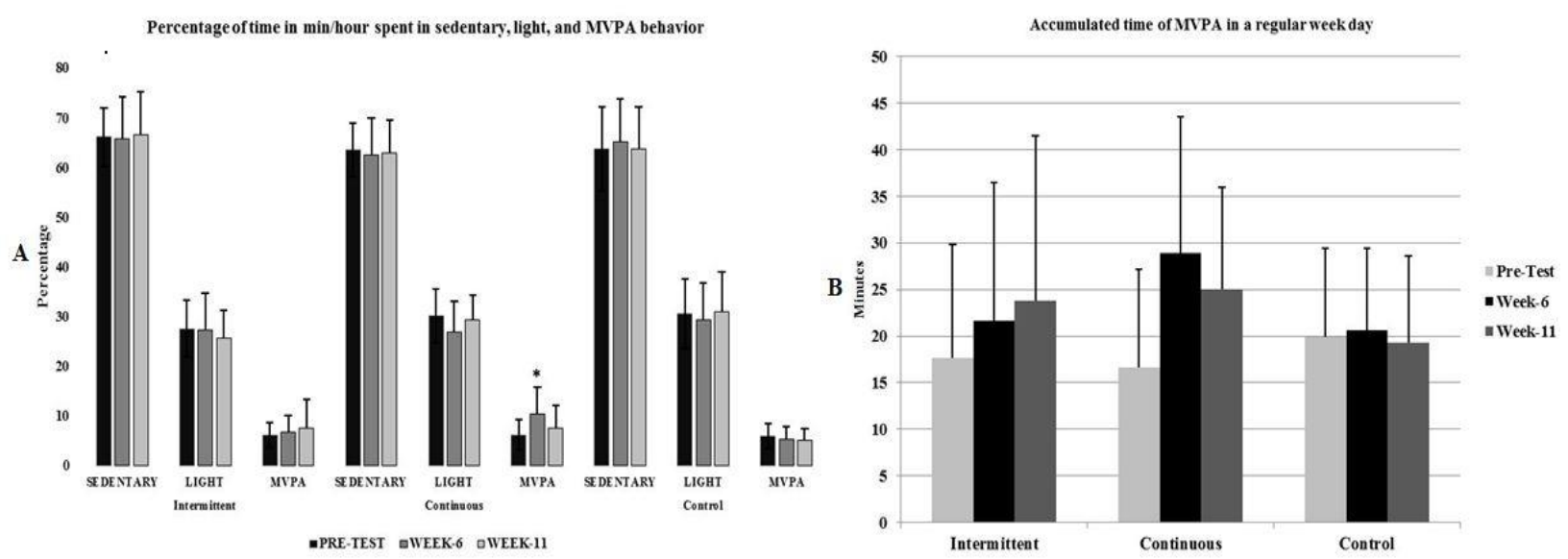

Figure 3A Time percentage per hour spent in sedentary, light, and MVPA, and 3B Example of time accumulated in a regular week day shown as MVPA.

*significantly different from pre-test $(p<0.05)$

\begin{tabular}{|c|c|c|c|c|c|c|c|c|c|c|c|c|c|c|}
\hline & & \multirow{2}{*}{$\begin{array}{l}\text { PRE- } \\
\text { TEST }\end{array}$} & \multirow[t]{2}{*}{ WEEK-6 } & \multirow[t]{2}{*}{ WEEK-11 } & \multicolumn{2}{|c|}{ Main effect of group } & \multicolumn{4}{|c|}{ Main effect of time } & \multicolumn{3}{|c|}{ Time by group interaction } & \multirow{2}{*}{$\begin{array}{c}\begin{array}{c}\text { Post- } \\
\text { Hoc }\end{array} \\
\mathbf{p}\end{array}$} \\
\hline & & & & & $\mathbf{F}$ & $\mathbf{p}$ & $\mathbf{n}^{2}$ & $\mathbf{F}$ & $\mathbf{p}$ & $\mathbf{n}^{2}$ & $\mathbf{F}$ & $\mathrm{p}$ & $\mathbf{n}^{2}$ & \\
\hline \multirow{3}{*}{$\begin{array}{l}\text { Overall } \\
\text { mired } \\
\text { ANOVA }\end{array}$} & Sedentary & & & & 1.318 & 0.275 & & 0.019 & 0.982 & & 0.440 & 0.780 & & \\
\hline & Light & & & & 2.067 & 0.135 & & 2.435 & 0.092 & & 1.605 & 0.177 & & \\
\hline & MVPA & & & & 3.963 & $0.024^{*}$ & .115 & 4.895 & $0.009^{*}$ & .074 & 4.688 & $0.001^{*}$ & .133 & \\
\hline \multirow{3}{*}{ Intermittent } & Sedentary & $66.2 \pm 5.9$ & $65.9 \pm 8.4$ & $66.6 \pm 8.7$ & & & & & & & & & & \\
\hline & Light & $27.6 \pm 5.6$ & $27.3 \pm 7.5$ & $25.7 \pm 5.6$ & & & & & & & & & & \\
\hline & MVPA & $6.2 \pm 2.6$ & $6.8 \pm 3.4$ & $7.7 \pm 5.7$ & & & & & & & & & & \\
\hline \multirow{3}{*}{ Continuous } & Sedentary & $63.6 \pm 5.4$ & $62.7 \pm 7.4$ & $62.97 \pm 6.5$ & & & & & & & & & & \\
\hline & Light & $30.2 \pm 5.4$ & $26.9 \pm 6.3$ & $29.4 \pm 4.98$ & & & & & & & & & & \\
\hline & MVPA & $6.21 \pm 3$ & $10.4 \pm 5.6$ & $7.62 \pm 4.6$ & & & & & & & & & & ** \\
\hline \multirow{3}{*}{ Control } & Sedentary & $63.8 \pm 8.5$ & $65.3 \pm 8.7$ & $63.9 \pm 8.4$ & & & & & & & & & & \\
\hline & Light & $30.6 \pm 7.1$ & $29.3 \pm 7.6$ & $30.9 \pm 8.1$ & & & & & & & & & & \\
\hline & MVPA & $5.6 \pm 2.6$ & $5.34 \pm 2.5$ & $5.18 \pm 2.24$ & & & & & & & & & & \\
\hline
\end{tabular}

Figure 4 Results of the mixed ANOVA in terms of percentage of time spent in sedentary, light, and MVPA behavior per group of intervention.

*Significantly different $(p<0.05)$

** Continuous group MVPA was significantly higher on week-6 compared to pre-test $(p<0.05)$. 
There was a significant effect of time by group interaction $f(2,64)=3.158, p=.049$. The Bonferroni Post-Hoc test shows a significant reduction on HbA1c from pre-test to post-test within the continuous group $(p=.005)$. There were no significant changes within the multiple break group $(p=.266)$ or control group $(p=.661)$. When analyzing the results by delta change, the continuous walking group showed a significant reduction of $\mathrm{HbA1c}$ by $0.16 \%$ ( 40 to $38 \mathrm{mmol} / \mathrm{mol}$ ) with a total mean change of $2.75 \%$ from pre-test to post-test.

The multiple breaks group reduced $\mathrm{HbA1c}$ by $0.06 \%$ (39 to $38 \mathrm{mmol} / \mathrm{mol}$ ) with a total mean change of $1.1 \%$ but it was not significant, and the control group increased $\mathrm{HbA} 1 \mathrm{c}$ levels by $0.02 \%(38 \mathrm{mmol} / \mathrm{mol})$ with a mean increment of $0.18 \%$.

\subsection{Physical activity results}

Accelerometer data were obtained and analyzed as time percentage per hour spent in sedentary, light intensity, MVPA bouts. Figure 3A shows the percentage of time per hour spent in each of those behaviors per intervention group. Figure 3B represents daily behavior in terms of MVPA; it reflects the MPVA bouts accumulation for all groups in a regular week day. Continuous group shows higher level of accumulated MVPA during waking time.

Figure 4 shows the Mixed ANOVA results as percentage of minutes per hour in sedentary, light, and MVPA in each intervention group. Participants in the continuous group significantly increased MVPA at week 6 and they were able to maintain higher levels of MVPA at the end of the intervention.

\section{Discussion}

The present study examined changes in $\mathrm{HbA} 1 \mathrm{c}$ for sedentary employees exposed to two different walking programs during a 10-week intervention. The results show that participants in the continuous group (20-to-40 minutes 3-to-5 days/week, 10-week intervention) reached moderate intensity walking within the continuous bout and showed significant reductions on glycated hemoglobin or HbA1c, potentially reducing the risk of developing type 2 diabetes and subsequent health disorders.

Our findings are in concordance with results from two meta-analyses $[43,10]$ showing programs that included 12 or more weeks of structured physical activity with more than 150 minutes per week were associated with significant $\mathrm{HbA1c}$ reductions compared to control participants. For our study, participants were not asked to participate in 150 minutes/week of walking until week 6 . In our free-living trial, experimental groups were asked to incrementally increase walking time from week 1 to the end of the program and were not asked to walk 150 minutes per week until week 6 (figure 1). The accelerometer analysis shows that both experimental groups spent on average less than 12 percent of the time in MVPA per hour. The continuous group spent in average almost 29 minutes in MVPA per bout on week 6 and 25 minutes on week 11 , approximately 10 percent (week6) and 8 percent (week-11) which may have stimulated physiologic pathways to significantly reduce $\mathrm{HbA1C}$ after almost three months. Exercise is a physiological stressor that affects the glucose homeostasis and energy balance through multiple hormonal activators and regulators, nervous system, regulators within the muscle and liver, which positively reduces glucose content [44]. Whereas, HbA1c in the intermittent group was reduced, changes were not significant. Based on these results changes in HbA1c might occur with longer bouts of MVPA and specific accumulation of MVPA during the day needs to be explored as intermittent physical activity seems to be important to break sedentary time and improve metabolic markers. Exercise prescription characteristics such us time, intensity, and frequency may play a fundamental role on glucose changes throughout walking interventions to produce significant changes on $\operatorname{HbA} 1 \mathrm{C}[16,45,46]$. For example a program with only 3 workouts per week was not enough to change glycated hemoglobin in a nonrandomized trial even though they accumulated more than 150 minutes per week [47]. In addition, the intensity of walking is an important determinant of HbA1c changes $[16,48]$. A group of scientists found exercise intensity as a predictor of $\mathrm{HbA1c}$ reductions [16], and other researchers concluded that moderate intensity walking significantly decreased glycated hemoglobin compared to the control participation [48], which may explain the lack of significance for the intermittent group due to the lower amount of moderate intensity accumulated throughout the day. The accelerometer data grouped in percentage of sedentary behavior, light intensity, and MVPA per hour, as well as the accumulated time of MVPA in a regular day, showed that the continuous group reached longer bouts of MVPA which could explain changes in HbA1c in this group. These results are supported by the study of Gay, Buchner, and Schmidt [49] who showed that the relationship between physical activity and $\mathrm{HbA1C}$ was associated with short bouts of MVPA ( 10minutes) 
for individuals at risk of developing T2D, the length of the MVPA bouts positively associates to HbA1c reductions. Like those findings, in our study we were able to see reduction on $\mathrm{HbA} 1 \mathrm{C}$ on those who achieved longer bouts of MVPA. Putting the results of both studies together $[48,49]$, there may be a specific doseresponse relationship that needs to be studied in further detail to determine the amount of MVPA that people need to perform to reduce the risk of developing T2D.

Early acute trials where intermittent physical activity was applied in short time bouts ( $2 \mathrm{~min}$ ) to see effects on glucose have shown that short bouts compared to continuous bouts of PA are a similar or better approach to control insulin and glucose excursions $[25,50]$. In our 10 -week study, intermittent physical activity did not reduce $\mathrm{HbA1c}$ significantly, possible explained by the lower levels of MVPA compared to the continuous trial. More research is required to explore the possible benefits of short versus long bouts of physical activity and specifically, accumulated MVPA effects on HbA1c sedentary adults at risk for developing TD2. Although the intermittent group was prescribed with the same dose of physical activity, this group participated in less MVPA and did not have significant changes in HbA1c. Intermittent activity throughout the day may be harder to regulate and reach a moderate pace. Short walking breaks with no supervision may be even harder to achieve the desired intensity when comparing to longer periods of walking, in which people have more time to improve exertion compared to the intermittent walking. In time percentage per hour, at week 6, the continuous walking group achieved significantly longer bouts of moderate intensity during their walking activity (10.4 $\pm 5.55 \%)$ compared to the intermittent walking group (6.79 $\pm 3.44 \%$ ) and control group (5.34 $\pm 2.5 \%)$. However, at week 11 , the continuous achieved shorter MVPA bouts $(7.62 \pm 4.59 \%)$ compared to week 6, intermittent walking group slightly increased MVPA (not significant) about $1 \%$ from week $6(7.7 \pm 5.68 \%)$, and the control group decreased MVPA $(5.18 \pm 2.24 \%)$. Further research is necessary to determine the effects of these two-walking program on long-term walking behavior and how long-term walking behavior relates to HbA1c.

We faced some limitations, we did not test for hemoglobin levels to compare with A1cNOW results, but previous validations have been performed [51-53]. We did not test participants for any other blood related disease (e.g. hemolytic anemia or other hemolytic disease, blood loss) that may change HbA1c levels and produce inaccurate readings.

The walking program was meant to replicate free living conditions to mimic how exercise prescriptions are giving in a clinical setting, thus, physical activity intensity and frequency were not recorded every day to ensure participants met the program prescription; however, participants indicated they following the instruction as asked, and participants were followed closely to ensure they were following the instructions and meeting recommendations. This is a major concern in this study; however, people's behavior is a real scenario that accounts when interventions are based on free living condition prescriptions.

\section{Conclusion}

Based on our results and previous reports, we conclude that long term continuous walking activity at moderate to vigorous intensity seems to be enough to reduce glycated hemoglobin percentages in adult sedentary employees. Since breaking sedentary time is a major concern to reduce health impairment risks, intermittent walking activity may have some positive impact on reducing $\mathrm{HbA} 1 \mathrm{c}$ percentages, however, further research is necessary to identify the dose of intermittent physical activity necessary to accumulate enough MVPA during the day to decrease HbA1c levels and reduce the risk of developing T2D on sedentary population.

\section{References}

[1] Marc T. Hamilton, Genevieve N. Healy, David W. Dunstan, Theodore W. Zderic and Neville Owen, Too Little Exercise and Too Much Sitting: Inactivity Physiology and the Need for New Recommendations on Sedentary Behavior, Current Cardiovascular Risk Reports, 2(4) (2008) 292-298. [DOI] [PubMed]

[2] Karin I Proper, Amika S Singh, Willem van Mechelen, Mai J M Chinapaw, Sedentary behaviors and health outcomes among adults: a systematic review of prospective studies, American Journal of Preventive Medicine, 40(2) (2011) 174-82. [DOI] [PubMed]

[3] E. Stamatakis, M. Hamer, and D.W. Dunstan, Screen-based entertainment time, all-cause mortality, and cardiovascular events: populationbased study with ongoing mortality and hospital events follow-up, Journal of the American College of Cardiology, 57(3) (2011) 292-9. [DOI] [PubMed] 
[4] Tatiana $Y$ Warren, Vaughn Barry, Steven $P$ Hooker, Xuemei Sui, Timothy S Church, Steven N Blair, Sedentary behaviors increase risk of cardiovascular disease mortality in men, Medicine and Science in Sports and Exercise, 42(5) (2010) 879-85. [DOI] [PubMed]

[5] Christie $Y$ Jeon, R Peter Lokken, Frank B Hu, Rob $M$ van Dam, Physical activity of moderate intensity and risk of type 2 diabetes: a systematic review. Diabetes Care, 30(3) (2007) 744-52. [DOI] [PubMed]

[6] F.B. Hu, R.J. Sigal, J.W. Rich-Edwards, G.A. Colditz, C.G. Solomon, W.C. Willett, F.E. Speizer, J.E. Manson, Walking compared with vigorous physical activity and risk of type 2 diabetes in women: a prospective study, Journal of the American Medical Association, 282(15) (1999) 1433-9. [DOI] [PubMed]

[7] R Graham Barr, David M Nathan, James B Meigs, Daniel E Singer, Tests of glycemia for the diagnosis of type 2 diabetes mellitus, Annals of Internal Medicine, 137(4) (2002) 263-72. [DOI] [PubMed]

[8] Douglas J Oberlin, Catherine R Mikus, Monica L Kearney, Pamela S Hinton, Camila Manrique, Heather J Leidy, Jill A Kanaley, R Scott Rector, John P Thyfault, One bout of exercise alters freeliving postprandial glycemia in type 2 diabetes, Medicine and Science in Sports and Exercise, 46(2) (2014) 232-8. [DOI] [PubMed]

[9] Matthew C Riddle, Julio Rosenstock, John Gerich, Insulin Glargine 4002 Study Investigators, The treat-to-target trial: randomized addition of glargine or human NPH insulin to oral therapy of type 2 diabetic patients, Diabetes Care, 26(11) (2003) 3080-6. [DOI] [PubMed]

[10] Daniel Umpierre, Paula A B Ribeiro, Caroline K Kramer, Cristiane B Leitão, Alessandra T N Zucatti, Mirela J Azevedo, Jorge L Gross, Jorge P Ribeiro, Beatriz D Schaan, Physical activity advice only or structured exercise training and association with HbA1c levels in type 2 diabetes: a systematic review and meta-analysis, JAMA, 305(17) (2011) 1790-9. [DOI] [PubMed]

[11] Matthew Hollings, Yorgi Mavros, Jonathan Freeston, Maria Fiatarone Singh, The effect of progressive resistance training on aerobic fitness and strength in adults with coronary heart disease: A systematic review and meta-analysis of randomised controlled trials, European Journal of Preventive Cardiology, 24(12) (2017) 12421259. [DOI] [PubMed]

[12] Judith C Kuenen, Rikke Borg, Dirk J Kuik, Hui Zheng, David Schoenfeld, Michaela Diamant, David M Nathan, Robert J Heine, ADAG Study Group, Does glucose variability influence the relationship between mean plasma glucose and HbA1c levels in type 1 and type 2 diabetic patients?, Diabetes Care, 34(8) (2011) 1843-7. [DOI] [PubMed]

[13] Monnier, L., H. Lapinski, and C. Colette, Contributions of fasting and postprandial plasma glucose increments to the overall diurnal hyperglycemia of type 2 diabetic patients: variations with increasing levels of $\mathrm{HbA}(1 \mathrm{c})$, Diabetes Care, 26(3) (2003) 881-5. [DOI] [PubMed]

[14] T.M. Wolever, J.L. Chiasson, A. Csima, J.A. Hunt, C. Palmason, S.A. Ross, E.A. Ryan, Variation of postprandial plasma glucose, palatability, and symptoms associated with a standardized mixed test meal versus $75 \mathrm{~g}$ oral glucose, Diabetes Care, 21(3) (1998) 336-40. [DOI] [PubMed]

[15] Ronald J Sigal, Glen P Kenny, Normand G Boulé, George A Wells, Denis Prud'homme, Michelle Fortier, Robert D Reid, Heather Tulloch, Douglas Coyle, Penny Phillips, Alison Jennings, James Jaffey, Effects of aerobic training, resistance training, or both on glycemic control in type 2 diabetes: a randomized trial, Annals of Internal Medicine, 147(6) (2007) 357-69. [DOI] [PubMed]

[16] N.G. Boulé, G.P. Kenny, E. Haddad, G.A. Wells, R.J. Sigal, Meta-analysis of the effect of structured exercise training on cardiorespiratory fitness in Type 2 diabetes mellitus, Diabetologia, 46(8) (2003) 1071-81. [DOI] [PubMed]

[17] T.D. Agurs-Collins, S.K. Kumanyika, T.R. Ten Have, L.L. Adams-Campbell, A randomized controlled trial of weight reduction and exercise for diabetes management in older AfricanAmerican subjects, Diabetes Care, 20(10) (1997) 1503-11. [DOI] [PubMed]

[18] Tapani Rönnemaa, Kari Mattila, Aapo Lehtonen, Veikko Kallio, A controlled randomized study on the effect of long-term physical exercise on the metabolic control in type 2 diabetic patients, Acta Medica Scandinavica, 220(3) (1986) 219-24. [DOI]

[19] N.G. Boulé, E. Haddad, G.P. Kenny, G.A. Wells, R.J. Sigal, Effects of exercise on glycemic control and body mass in type 2 diabetes mellitus: a meta-analysis of controlled clinical trials, Journal of the American Medical Association, 286(10) (2001) 1218-27. [DOI] [PubMed]

[20] D. Tessier, J. Ménard, T. Fülöp, J. Ardilouze, M. Roy, N. Dubuc, M. Dubois, P. Gauthier, Effects of aerobic physical exercise in the elderly with type 2 diabetes mellitus, Archives of Gerontology and Geriatrics, 31(2) (2000) 121-132. [DOI] [PubMed]

[21] Alison J Dunkley, Danielle H Bodicoat, Colin J Greaves, Claire Russell, Thomas Yates, Melanie J Davies, Kamlesh Khunti, Diabetes prevention in the real world: effectiveness of pragmatic lifestyle interventions for the prevention of type 2 diabetes and of the impact of adherence to 
guideline recommendations: a systematic review and meta-analysis, Diabetes Care, 37(4) (2014) 922-33. [DOI] [PubMed]

[22] D.E. Laaksonen, et al., Physical activity in the prevention of type 2 diabetes: the Finnish diabetes prevention study, Diabetes, 54(1) (2005) 158-65. [DOI] [PubMed]

[23] Matthew McCarthy, Charlotte L Edwardson, Melanie J Davies, Joseph Henson, Laura Gray, Kamlesh Khunti, Thomas Yates, Change in Sedentary Time, Physical Activity, Bodyweight, and Hba1c in High-Risk Adults, Medicine and Science in Sports and Exercise, 49(6) (2017) 1120-1125. [DOI] [PubMed]

[24] Paddy C Dempsey, Neville Owen, Stuart J H Biddle, David W Dunstan, Managing sedentary behavior to reduce the risk of diabetes and cardiovascular disease, Current Diabetes Reports, 14(9) (2014) 522. [DOI] [PubMed]

[25] Michael Holmstrup, Timothy Fairchild, Stefan Keslacy, Ruth Weinstock, Jill Kanaley, Multiple short bouts of exercise over $12-\mathrm{h}$ period reduce glucose excursions more than an energymatched single bout of exercise, Metabolism, 63(4) (2014) 510-9. [DOI] [PubMed]

[26] Kristian Karstoft, Camilla S Christensen, Bente K Pedersen, Thomas P J Solomon, The acute effects of interval- Vs continuous-walking exercise on glycemic control in subjects with type 2 diabetes: a crossover, controlled study, Journal of Clinical Endocrinology \& Metabolism, 99(9) (2014) 3334-42. [DOI] [PubMed]

[27] E. Valenti, The effects of continuous exercise versus intermittent exercise on glucose levels in sedentary individuals, in Department of Exercise and Sport Science. 2013, University of Central Missouri: UNIVERSITY OF CENTRAL MISSOURI, WARRENSBURG, MISSOURI.

[28] M. Rodriguez-Hernandez, and D.W. Wadsworth, The effect of 2 walking programs on aerobic fitness, body composition, and physical activity in sedentary office employees, PLoS One, 14(1) (2019) e0210447. [DOI] [PubMed]

[29] M.G .Rodriguez-Hernandez, and D.W. Wdasworth, A walking intervention for sedentary employees: effects on self-regulation and selfefficacy. Pensar en movimiento: Revista de ciencias del ejercicio y la salud, 18(1) (2020) 117. [DOI]

[30] J.D. Cohen, Statistical Power Analysis for the Behavioral Sciences 2nd Edition ed. 1988, Hillsdale, NJ: Lawrence Erlbaum Associates, Publishers.

[31] National Glycohemoglobin Standardization Program. Harmonizng Hemoglobin A1c Testing, http://www.ngsp.org/ Acessed on 2/14/2017.

[32] Polymer Technology Systems, I., A1cNOW+ Professional-Use Product Insert.
[33] John, D. and P. Freedson, ActiGraph and Actical physical activity monitors: a peek under the hood, Medicine and Science in Sports and Exercise, 44(1 Suppl 1) (2012) S86-9. [DOI] [PubMed]

[34] Cain, K.L. and C.M. Geremia, Accelerometer Data Collection and Scoring Manual for Adult \& Senior Studies. 2012.

[35] Dianne S Ward, Kelly R Evenson, Amber Vaughn, Anne Brown Rodgers, Richard P Troiano, Accelerometer use in physical activity: best practices and research recommendations. Medicine and Science in Sports and Exercise, 37(11 Suppl) (2005) S582-8. [DOI] [PubMed]

[36] S.G. Trost, K.L. McIver, and R.R. Pate, Conducting accelerometer-based activity assessments in field-based research, Medicine and Science in Sports and Exercise, 37(11 Suppl) (2005) S531-43. [DOI] [PubMed]

[37] Charles E Matthews, Kong $Y$ Chen, Patty S Freedson, Maciej S Buchowski, Bettina M Beech, Russell R Pate, Richard P Troiano, Amount of time spent in sedentary behaviors in the United States, 2003-2004, American Journal of Epidemiology, 167(7) (2008) 875-81. [DOI] [PubMed]

[38] Teresa L Hart, Ann M Swartz, Susan E Cashin, Scott J Strath, How many days of monitoring predict physical activity and sedentary behaviour in older adults?, International Journal of Behavioral Nutrition and Physical Activity, 8 (2011) 62. [DOI] [PubMed]

[39] Richard P Troiano, David Berrigan, Kevin W Dodd, Louise C Mâsse, Timothy Tilert, Margaret McDowell, Physical activity in the United States measured by accelerometer. Medicine and Science in Sports and Exercise, 40(1) (2008) 181-8. [DOI] [PubMed]

[40] C. Tudor-Locke, W.D. Johnson, and P.T. Katzmarzyk, Accelerometer-determined steps per day in US adults, Medicine and Science in Sports and Exercise, 41(7) (2009) 1384-91. [DOI] [PubMed]

[41] D. J. Chinn, M. White, J. Harland, C. Drinkwater, and S. Raybould, Barriers to physical activity and socioeconomic position: implications for health promotion, Journal of Epidemiology and Community Health, 53(3) (1999) 191-192. [DOI] [PubMed]

[42] Linke, S.E., L.C. Gallo, and G.J. Norman, Attrition and adherence rates of sustained vs. intermittent exercise interventions, Annals of Behavioral Medicine, 42(2) (2011) 197-209. [DOI] [PubMed]

[43] Snowling, N.J. and W.G. Hopkins, Effects of different modes of exercise training on glucose control and risk factors for complications in type 2 diabetic patients: a meta-analysis, Diabetes Care, 29(11) (2006) 2518-27. [DOI] [PubMed] 
[44] Riddell, M. and B.A. Perkins, Exercise and glucose metabolism in persons with diabetes mellitus: perspectives on the role for continuous glucose monitoring, Journal of Diabetes Science and Technology, 3(4) (2009) 914-23. [DOI] [PubMed]

[45] Kristian Karstoft, Kamilla Winding, Sine H Knudsen, Jens S Nielsen, Carsten Thomsen, Bente $\mathrm{K}$ Pedersen, Thomas $\mathrm{P} \mathrm{J}$ Solomon, The effects of free-living interval-walking training on glycemic control, body composition, and physical fitness in type 2 diabetic patients: a randomized, controlled trial, Diabetes Care, 36(2) (2013) 22836. [DOI] [PubMed]

[46] P. Manjoo, L. Joseph, and K. Dasgupta, Abdominal adiposity and daily step counts as determinants of glycemic control in a cohort of patients with type 2 diabetes mellitus, Nutrition and Diabetes, 2 (2012) e25. [DOI] [PubMed]

[47] Tomas Fritz, Per Wändell, Hans Aberg, Peter Engfeldt, Walking for exercise--does three times per week influence risk factors in type 2 diabetes?, Diabetes Research and Clinical Practice, 71(1) (2006) 21-27. [DOI] [PubMed]

[48] Shanhu Qiu, Xue Cai, Uwe Schumann, Martina Velders, Zilin Sun and Jürgen Michael Steinacker, Impact of walking on glycemic control and other cardiovascular risk factors in type 2 diabetes: a meta-analysis, PLoS One, 9(10) (2014) e109767. [DOI] [PubMed]

[49] J.L. Gay, D.M. Buchner, and M.D. Schmidt, Doseresponse association of physical activity with $\mathrm{HbA1c}$ : Intensity and bout length, Preventive Medicine, 86 (2016) 58-63. [DOI] [PubMed]

[50] David W Dunstan, Bronwyn A Kingwell, Robyn Larsen, Genevieve N Healy, Ester Cerin, Marc T Hamilton, Jonathan E Shaw, David A Bertovic, Paul Z Zimmet, Jo Salmon, Neville Owen, Breaking up prolonged sitting reduces postprandial glucose and insulin responses, Diabetes Care, 35(5) (2012) 976-83. [DOI] [PubMed]

[51] Justin R. Arrendale, Sonia E. Cherian, Issam Zineh, Mark J. Chirico, James R. Taylor, Assessment of glycated hemoglobin using A1CNow $+{ }^{\mathrm{TM}}$ point-of-care device as compared to central laboratory testing, Journal of Diabetes Science and Technology, 2(5) (2008) 822-827. [DOI] [PubMed]

[52] Bruce W. Bode, Benjamin R. Irvin, Jeffrey A. Pierce, Michael Allen and Annette L. Clark, Advances in hemoglobin A1c point of care technology, Journal of Diabetes Science and Technology, 1(3) (2007) 405-11. [DOI] [PubMed]

[53] A.W. Carter, An analysis of the assessment of glycated hemoglobin using A1cNow+ point-ofcare device compared to central laboratory testing--an important addition to pharmacistmanaged diabetes programs?, Journal of Diabetes Science and Technology, 2(5) (2008) 828-830. [DOI] [PubMed]

\section{Acknowledgement}

We would like to thank Dr. Mike Roberts and Dr. David Pascoe for their collaboration on this study, as well to the collaborative team that made this project possible. Thanks to the participants for their time devoted. The results of this study are presented clearly, honestly, and without fabrication, falsification, or inappropriate data manipulation, and the results obtained in this study do not constitute any endorsement.

\section{Funding}

No funding was received to carry out this study

Ethics approval

This study was approved by Institutional ethics committee.

\section{Authors Contribution \\ Mynor Rodriguez-Hernandez - Conceived the study design, methodology and analysis Collected the data, Performed the analysis, Wrote the paper. James R. McDonald - Contributed to the study design, Proved and edited the paper. Danielle W. Wadsworth -Contribute to the study design and analysis, contributed to the data analysis, Edited and proved the manuscript.}

Does this article screened for similarity? Yes.

Conflict of interest

The authors have no conflicts of interest to declare that they are relevant to the content of this article.

Informed consent

Written consent was obtained from the participants

About The License

(C) The author(s) 2021. The text of this article is open access and licensed under a Creative Commons Attribution 4.0 International License 